\title{
Digital Media as Support for Technical Vocational Training: Expectations and Research Results of the Use of Web2.0
}

\author{
http://dx.doi.org/10.3991/ijac.v7i3.4013 \\ Sven Schulte, Tim Richter, Torsten Grantz \\ Institute Technology and Education (ITB), Bremen, Germany
}

\begin{abstract}
Digital media as support for Technical Vocational Education and Training (TVET) learning processes have been increasingly tested in recent times. In Germany, for example, the Ministry for Education and Research and others have been supporting projects that develop and evaluate innovative didactical and technological models focusing on "Virtual Learning", "Learning with Web2.0" or "Mobile Learning". Above all, in vocational education, and with regard to the target group of media-affine young people, teachers have high expectations regarding pedagogical purposes, and learning efficiency. The present article describes a project on a learning and communication platform that combines the advantages of digital media with the special feature of a cooperation of learning environments within the German Dual TVET System by making use of innovative pedagogical approaches for the shaping of more sustainable occupational learning. The results show examples of how a different (often quite unexpected) use of digital media for vocational learning processes by young people is justified.
\end{abstract}

Index Terms-Learning with digital media, training, Dual System in TVET

\section{INTRODUCTION}

\section{A. Developments and expectations - Digital media as learning support}

Every new, or further, development of media entails questions asked by the educational sciences regarding new and didactically justifiable fields of application to enhance learning [cf. 1]. Nevertheless, it is difficult to keep pace with the technological development, and there are always high expectations with regard to the new technologies when it comes to learning efficiency.

The first important phase began with the use of personal computers in the 1980s. First forms of e-learning were developed at that time. However, the learning success that was first and foremost based on the learning of factual knowledge, and on acquiring information, did not reveal the expected sustainable advantages in terms of the expenditure of learning and time. At the beginning of the new millennium, the internet had already become commonplace, and the subsequent prevalence of Web2.0 applications again raised high expectations in pedagogues and teachers: the interactive possibilities (and the references to self-organized learning and individual learning motivation) were applied in schools, initial and further training in the form of learning platforms which were partly successful; however, most of them remained with- out the desired impact. Now, the next major trend is emerging: smartphones and tablet PCs support mobile learning, and enable the individual learners - e.g. in the form of micro-learning-units - to significantly codetermine, and control factors such as learning pace, learning contents, location and time.

This short retrospective and outlook alone underpins the multitude of pedagogical possibilities to make use of digital media as a support for learning. Nevertheless expectations are back to normal, and it is well known that it is the organizational framework, the didactical concept, and the target group that determine the use of digital media. In order to give more background information on the project "expertAzubi", we will provide a concise description of a special feature of the German TVET system.

\section{B. The Dual System as a special feature of vocational education and training in Germany}

The Dual System is the central characteristic feature of TVET in Germany [cf. 2] [cf. 3]. During the training, two learning environments - the vocational school and the training company - are interlinked in order to impart essential knowledge, on the one hand, and practical skills, on the other hand. Due to the cooperation of these two learning environments, learning is coordinated in a way that theoretical basics can be applied during practical work, or practical elements can be reflected within the learning contents at school.

One of the central elements is the report portfolio. The report portfolio is written by the trainees and regularly documents the themes and tasks dealt with and carried out at school and in the training company. In the first place, the report portfolio is a compulsory element of the training, and also provides the documented proof that both learning environments meet their obligations. The report portfolio can also serve to enhance the overall training quality (by a coordination of the topics between school and company). At least the companies are confident that reflection and learning processes could be encouraged in the trainees, beyond a mere performance of duties [cf. 4].

The Dual System is currently still the first choice for around 60 percent of all young persons of an age group who are starting vocational training [cf. 5]. In addition, there is full-time schooling and an expanding transition system for young people who - for different reasons were not able to get a training position. They can catch up with graduations, or enhance their education, prior to applying again for a training position in companies by presenting new certificates of qualification. The model of 
Dual System is in high international esteem. Above all the link-up of school and theory-based education (learning environment vocational school) and the work-process oriented coping with acting oriented work tasks (in the company) seem to be appropriate for the training of qualified junior skilled workers.

\section{EXPERTAZUBI ${ }^{1}$ : THE LERNING AND COMMUNICATIONS PLATFORM FOR TRAINEES AND EXPERTS}

The research project expertAzubi has first and foremost investigated the use of Web2.0 functionalities within TVET. A learning platform was developed that concentrates on the exchange of specialist know-how between trainees and experts (trainers, teachers, skilled workers), and that makes use of the technical potential of the digital media. In order to make use of the learning platform and to shape it in a didactically adequate way, the implementation process concentrated on the following elements:

PortfolioOnline: The report portfolio as a central element of the documentation of tasks and learning contents within the training was designed as a digital version. According to the situation and the requirements of the company, the PortfolioOnline can also be set up in the usual variants of daily, weekly or project reports. Similar to the "classical" report portfolio, the written entries will be read (on the platform) and approved online by the tutoring trainer, provided everything is factually and formally correct (a major prerequisite for the registration for the final exam, and eventually the graduation). In addition the trainer can also ask a reflection question after approval in order to encourage the trainee to delve deeper into the described topic. Even if this question and a possible answer will have no consequences for the grading of the report portfolio, the trainee is ideally being motivated for sustainable learning across the learning environments. However, this requires a careful reflection of the report portfolio entry by the trainee [cf. 6].

On the whole the report portfolio is not only a compulsory element for the trainee, but is also considered a central point for enhancing the quality of the training contents and the sustainability of learning. These arguments are picked up by expertAzubi as good report portfolios can also be made available to the entire learning community after a consultation between trainees and trainers. Thus these portfolios can be thematically arranged and serve as best-practice examples, as learning aids, or as a means of specialist exchange with other trainees of the same or of comparable occupations. They could also become part of the subject themes dealt with in vocational schools.

Blog-function and recommender: The second outstanding characteristic of expertAzubi was the use of a blogfunction. This function is, in fact, no innovative element in terms of technology. Within the platform, blogs can nevertheless help to exchange contents and specialist issues between the user groups (such as e.g. vocational school classes, trainees in a company, group of beginners and experts on a topic). An expert (teacher, trainer) provides requirements and motivation to create blogs that are subsequently commented, enhanced with links or files, or

\footnotetext{
${ }^{1}$ The project expertAzubi has been supported by funds of the Bundesministerium für Bildung und Forschung - BMBF (German Federal Ministry for Education and Research) and the European Union - ESF
}

opened for discussion by other blogs. A so-called recommender will support the thematic discussions on the platform. Based on the profile and the entries of the participants of the platform, he or she recommends other entries or the contact to other users with similar specialist or interest-motivated relevance.

Portfolio-Approach: In a pedagogical context a portfolio is applied in the sense of subject-orientated and/or constructivist learning theories as a concept to initiate and implement self-organized learning processes. The necessary and target group related criteria for the shaping of the portfolio refer to the choice of contents, the forms of presentation, assessment criteria, and characteristics for the learners' reflection. Two approaches out of numerous options for the use of portfolios were implemented in the project expertAzubi: First of all, the learning portfolio provides a structure which can be useful for trainees for the documentation of the competences they acquired in formal and informal learning situations. They can also take down what they still have to learn or would like to deepen. The recommender system automatically provides recommendations of documents and persons that are likely to offer assistance. It is, however, important that the learning portfolio cannot only be used during the training course, but may further be referred to in the working life of the trainees. Secondly, an application portfolio can be generated from the learning portfolio. It provides structures that are linked to official requirements such as e.g. Europass. Documentation on special abilities, successes, work results etc., can be compiled in a virtual portfolio for different requirements.

The project has been put to a test in north-western Germany. This region is marked by a great number of small enterprises and handicraft businesses, and runs regional training centers that cater for the school part of vocational education and training. These framework conditions proved to be perfect to test the advantages of a location-independent, digital learning platform as support for sustainable learning within the Dual System that is not confined to certain locations.

\section{RESEARCH QUESTIONS AND RESEARCH METHODS}

The project has investigated research questions focusing on the way young people are making use of digital media in the context of vocational learning. Compared to the private use of media and a visible media competence in young people resulting thereof, the following aspects were more deeply looked into:

1. How do young people deal with digital media in their private and occupational context?

2. What are the motives for the use of digital media in the context of learning?

3. How can the contents quality of User Generated Contents be assessed in the occupational context?

Two surveys were conducted in search for answers to the research questions. First, a quantity oriented target group analysis among the trainees in the project participants' companies tried to identify, how young people make use of digital media in their private and professional lives (sample: $n=95$ ). We also looked at the characteristics of self-organized learning and the motives for the use of media for learning purposes. In addition, comparable empirical studies for the target group of trainees were evaluated. The answers were evaluated in a descriptive 
way in order to depict the use of media in a private and occupational context. On the other hand we conducted correlation analyses that point at a presumed impact of the ability for self-organized learning on the way of media use.

The second - qualitative - survey is based on the method of group interviews; 63 young people were interviewed by two researchers in 14 group interviews, with 2 to 8 young people each. The interviews concentrated to three leading questions: 1 . What are your tasks during your training? 2. How do you generally make use of the Internet? 3. How do you make use of the internet for your training? Further questions were derived from the course of the conversations. The interviews were transcribed and evaluated with the aid of a documentary analysis. This means that content-related summaries were set up and text passages with a high emotional engagement of the interviewees were interpreted in order to understand their individual experiences [cf. 7].

\section{RESULTS}

With regard to the above-mentioned questions, the results of the survey provided the following answers:

1. How do young people deal with digital media in their private and occupational contexts?

Considering the descriptive outline of the target group analysis it turned out that PC and Web2.0 applications were considerably more frequently used in the private context than in the occupational environment. Compared to the expectations of the researchers, the frequency of use of Web2.0 applications was considerably low. Typical Web2.0 applications and activities in forums or blogs (both actively and passively) only played a marginal role in the private and occupational lives of the surveyed target group.

Statistically meaningful correlations between the frequency of private and occupational use of PC applications and the amount of self-organized learning could only be proved for Office applications. The analysis of the frequency of Web2.0 applications for private use showed correlation with the characteristic of self-organized learning. As for the occupational environment, positive correlations (significance 5\%) for the characteristic of the indicator for self-organized learning were revealed with regard to the use of learning videos. An even higher significance level could be identified for general and targeted Internet research.

On the whole, the young people lived up to the researchers' expectations and showed a high affinity to media, when asked about private areas and past-time activities. In the context of the training and for learning purposes above all the presumed innovative Web2.0 applications were significantly less frequently used. The qualitative survey was therefore explicitly evaluated under these aspects and concerned the second question:

2. What are the motives for the use of digital media in the context of learning?

The interview analyses reveal that the use of the Internet is strongly influenced by the training situation. The entry into a dual system vocational training is not just a simple continuation of the school career, but entails a significant change of milieu and triggers three important development tasks for trainees [cf. 8]. Thus the use of media recedes into the background:
Development of adequate learning concepts: Pupils often have learning concepts that are strongly influenced by an orientation towards the teacher and his or her assessments ("learning for the test"). These concepts must be replaced by vocational learning concepts focused on real objects. As a rule this is initiated by the confrontation with authentic work tasks.

Development of concepts of occupational work: During their training, the young people should learn how to get to know and how to ponder standards of occupational work such as quantity, quality, efficiency; routines should emerge as well as ideas how to improve technology and work organization. The interviews reflect this development task: the trainees should, for example, differentiate between knowledge imparted at school and in the training company.

Integration into the community of practice: When coping with the third development task, the orientation towards the peer group becomes less important and is replaced by an orientation towards colleagues and skilled workers in the companies. The interviews revealed, for example, that trainees can name hierarchies and rules stipulated by the companies, and that they are looking for ways to cope with them. In terms of the use of digital media, this means that some trainees declare that they do not - or only when being explicitly asked - reveal any advance of knowledge they may have acquired by a research in the Internet.

3. How can the contents quality of User Generated Contents be assessed in the occupational context?

With a general view on the first two questions, the answer to the third question is already evident: the occupational socialization by the specialist community of practice matters to the young people and exerts influence on their use of the Internet. The local involvement, the dependencies of a training relationship, and the need for commitment and reliability of the specialist basics have an impact on the learning behavior during the training and thus form a "primate of practice" with regard to digital sources of information. In addition, above all, handicraft occupations still require experience rather than knowledge. Thus, the internet as a basis for information is not prioritized. This also applies to organizational aspects: sensitive technical appliances are only suitable for building sites or workshops to a limited extent and the workprocess does not always allow spending time for research and a digital exchange of information.

The orientation towards practical actions also changes the attitudes towards information retrieved from the internet: at vocational schools it is, above all, important that the retrieved information fits into the scheme of a presentation; whereas the company requires that occupational acting has to rely on a statement. This is why a more critical attitude towards the Internet is developing during the training - along with a sustainable learning concept and a concept for occupational work. This is possibly a reason for showing restraint for the use of the Internet in the occupational context.

\section{CONCLUSIONS AND OUTLOOK}

The findings and experiences of the project lead to the following conclusions:

As already elaborated, the trainees' affinity for Web2.0 in their spare time, the thus developed media competence, 
and already existing platforms are not adequate reasons for becoming active online during a training course. It seems that vocational education and training with its local involvement, commitment and taking over of responsibility does not fit into the logic of the internet that is marked by anonymity, lack of obligation and globalism. In addition, there is tension between (vocational) schools and the internet. This tension refers to the power of definition of truth and relevance (the teacher or the trainer "determines" what is right while the Internet source does not give any "guarantee". This is above all crucial in the context of examinations during the training), and the consequences of having to admit nescience (fear of stigmatization). These are the contradictions the trainees have to deal with if they are requested to use a learning platform like expertAzubi.

As soon as the internet affine generation take over positions in schools and companies, it is expected that the use and the assessment of the internet - and thus its legitimacy for occupational work and learning will change in the medium term and that learning platforms and digital media will increasingly be used for learning processes [cf. 9]. This development should be monitored from a pedagogical point of view, and should be supported by adequate didactical concepts. Teachers, trainers, and experts in the companies should promote and accompany ways to sustainable and reflective learning.

\section{REFERENCES}

[1] G. Spöttl and S. Schulte, ,Work place orientated learning with digital media - consequences for competency development. ICELW 2012. New York.

[2] M. Fazekas and S. Field, "A Skills beyond School Review of Germany", OECD Reviews of Vocational Education and Training, OECD Publishing, 2013.

[3] K.A. Hensen and U. Hippach-Schneider, "VET in Europe - Country Report Germany“, Cedefop Refernet, Federeal Institute for Vocational Education and Training, 2012.
[4] T. Scheib, G. Spöttl and L Windelband, „Entwicklung einer Konzeption für eine Modellinitiative zur Qualitätsentwicklung und -sicherung in der betrieblichen Berufsausbildung. Band 4 der Reihe Berufsbildungsforschung“, Bertelsmann Verlag Bielefeld, Bundesministerium für Bildung und Forschung, 2006.

[5] BMBF (German Federal Ministry for Education and Research), „Berufsbildungsbericht“, Berlin, 2012.

[6] J. Burchert and S. Schulte, ,Qualität in der beruflichen Bildung Ansatz und Ziel der Reflexion von Berichtshefteinträgen“, In: bwp@ Berufs- und Wirtschaftspädagogik- Online, Ausgabe 21 (Dezember 2011), Online: http://www.bwpat.de/content/ausgabe/21/burchert-schulte/

[7] J. Buchert and S. Schulte, „Die Nutzung des Internets in der Ausbildung", Peter Lang Verlag, Frankfurt am Main, 2014.

[8] R. J. Havighurst, "Development tasks and education", New York \& London, 1972.

[9] German Federal Ministry for Education and Research, "Report on Vocational Education an Training”, 2013.

\section{AUTHORS}

Sven Schulte is Research Assistant of the Institute Technology and Education (ITB) at the University of Bremen, Am Fallturm 1, 28359 Bremen, Germany. (e-mail: sven.schulte@uni-bremen.de).

Tim Richter is Research Assistant of the Institute Technology and Education (ITB) at the University of Bremen, Am Fallturm 1, 28359 Bremen, Germany. (e-mail: tim.richter@uni-bremen.de).

Torsten Grantz is Research Assistant of the Institute Technology and Education (ITB) at the University of Bremen, Am Fallturm 1, 28359 Bremen, Germany. (e-mail: tgrantz@uni-bremen.de).

This work is supported by funds of the Bundesministerium für Bildung und Forschung - BMBF (German Federal Ministry for Education and Research) and the European Union (ESF). It is an extended and modified version of a paper presented at ICELW 2014, the Seventh Annual International Conference on E-learning in the Workplace, held from June 11-13, 2014 in New York. Submitted 15 March 2014. Published as resubmitted by the authors 14 October 2014. 